\title{
Arenga Pinnata-Silicone Biocomposite Properties via Experimental and Numerical Analysis
}

\author{
Siti Humairah KAMARUL BAHRAIN, Jamaluddin MAHMUD*, \\ Muhammad Hussain ISMAIL
}

\author{
Faculty of Mechanical Engineering, Universiti Teknologi MARA, 40450 Shah Alam, Selangor, Malaysia \\ crossref http://dx.doi.org/10.5755/j01.ms.24.3.18296
}

Received 02 June 2017; accepted 12 October 2017

\begin{abstract}
Due to high flexibility and elasticity, silicone rubber has been widely used in many applications especially in medical and industrial sectors. However, pure silicone rubber experiences weak tensile strength and this can be improved via filler addition. Therefore, this paper aims to produce a new type of silicone biocomposite (Arenga pinnata-silicone biocomposite) and assess its mechanical properties, physical properties and morphological characteristics. The effects of Arenga pinnata filler on the silicone rubber are investigated by comparing the mechanical properties between pure silicone rubber and $12 \mathrm{wt} \%$ Arenga pinnata-silicone biocomposite. Uniaxial tensile test was conducted on these soft materials to obtain stress-strain data, which then converted into engineering stress-stretch $\left(\sigma_{\mathrm{E}}-\lambda\right)$ data. These experimental data were fitted to Neo-Hookean and Mooney-Rivlin models to acquire the material constants. Its physical characteristic was studied via density test and the morphological surface on the break surface was examined using Scanning Electron Microscope (SEM). The average maximum tensile strength of the specimen with the addition of $12 \mathrm{wt} . \%$ Arenga pinnata filler is found to be $0.65 \mathrm{MPa}$. This signifies a decrease of its strength compared to pure silicone rubber (average maximum tensile strength $=0.85 \mathrm{MPa}$ ). However, in contrary, it is found that the presence of Arenga pinnata fibre has increased the stiffness and density of the silicone rubber. When comparing to experimental data, it could be observed that both Neo-Hookean and Mooney-Rivlin models could mimic better the elastic behaviour of the $12 \mathrm{wt}$ \% Arenga pinnata-silicone biocomposite compared to pure silicone rubber. Observing the SEM images, no agglomerations of Arenga pinnata filler can be seen thus conforming good dispersion of the filler. The images also show good fibre adhesion between the filler and the matrix. Therefore, it can be concluded that the addition of Arenga pinnata filler has enhanced properties of pure silicone rubber. In addition, this study promotes the benefits of utilising natural fibres as fillers in composite materials.

Keywords: Arenga pinnata fibre, silicone biocomposite, hyperelastic materials, mechanical properties.
\end{abstract}

\section{INTRODUCTION}

Recently, growing concerns regarding environmental issues especially on global warming have arisen. One of the major contributing factors to this climate issue is anthropogenic carbon dioxide $\left(\mathrm{CO}_{2}\right)$ emissions due to the burning of plastics and synthetic fibres [1-3]. Furthermore, synthetic fibres too may cause harm and irritation to the users. Due to the aforementioned issues, natural fibres are widely explored and studied to replace synthetic fibres [2]. Natural fibres are also promoted as an alternative to overcome these climate change problems by lessen the emissions of the $\mathrm{CO}_{2}$ gases as they are known for their biodegradable and renewable properties.

Natural fibres are inexpensive, also possess some unique properties such as low density to easy to be processed, abundance, no tendency to corrosion and most importantly they promote eco-friendly materials, which are safe to be handled [4,5]. Among popular natural fibres are kenaf, hemp, bamboo and oil palm have widely been discovered by worldwide researchers especially in hard matrix composites such as epoxy and polyester to seek its potential as reinforcements in composite materials.

Unlike synthetic fibres, natural fibres, which are mainly composed of chemical composition such as hemicellulose, lignin and pectin, are normally facing hydrophilic characteristic, which allows them to absorb moisture and resulted in low compatibility and weak adhesion [6]. This in contrast has to be improved when combining with hydrophobic matrix in order to allow good fibre-matrix bonding [7].

Arenga pinnata fibre is one of the growing attentions in the study of potential natural fibres [8], which has been reinforced into epoxy, unsaturated polyester and phenolic matrices (hard biocomposite materials) [9]. Therefore, this has motivated this study to discover the mechanical and physical properties when the Arenga pinnata fibre is reinforced into silicone rubber to produce a soft biocomposite material. The Arenga pinnata tree or also known by its scientific name; Arenga saccharifera tree [9] can be found in tropical country like Malaysia, Philippines and Indonesia. Normally, the tree grows wild at foot hill or lower hill slopes amidst other wild trees. The tree also grows individually and scattered in several places in Kuala Pilah, Negeri Sembilan, Malaysia. Uniquely, all parts of the tree have its own benefits, which can be processed and produce as products which are commercialized by the local people [10]. For example, the palm sap of the tree is traditionally used as a sweetener known as gula enau after it has been processed and the sap also known to be among famous

\footnotetext{
* Corresponding author. Tel.: +603-55435161.

E-mail address: jm@salam.uitm.edu.my (J Mahmud)
} 
beverage besides coconut juice $[11,12]$. The fibres, on the other hand, possessed high durability as they are traditionally being used by the locals to make roofs, brooms, mats and brushes. The fibres are also said to exhibit good seawater resistance due to the fibres were used as ropes for ship cordages [10].

However, the use of natural fibres with rubber-like materials has gained little attention by researchers and this study intends to introduce one using silicone rubber as the matrix. Previously, carbon nanotubes [13], alumina [14], graphite nanoplatelets [15] and silica [16] are among chosen fillers added into silicone rubber. The main purpose of the filler addition is mainly to improve drawbacks in silicone rubber as it exhibits poor thermal stability, weak mechanical properties and dielectric properties [14, 17]. Therefore, Arenga pinnata fibres are chosen in this study to enhance the properties of silicone rubber from the benefits possessed by the natural fibre itself. In addition, from the literature, it is found that the reinforcement of Arenga pinnata fibre into silicone rubber has not been reported earlier.

In terms of elastic modelling, it is found that a few researches have been conducted on soft materials and tissues such as human skin [18], rubber [19], and murine skin [20] that employ hyperelastic theories to obtain material constants. Neo-Hookean, Mooney-Rivlin, Ogden, Yeoh and Gent are among established models used to demonstrate the high deformations behaviour with nonlinear elastic properties especially for rubber-like materials [21]. Nevertheless, the material constant for Arenga pinnata-silicone biocomposite has not been established.

Therefore, this study for the first time aims to introduce a new silicone biocomposite material by reinforcing Arenga pinnata fibres into silicone rubber and report its mechanical properties, physical properties and morphological characteristics. This study is novel, as no similar approach to produce and assess the Arenga pinnata-silicone biocomposite's properties have been reported before. Moreover, in this study the hyperelastic material constants of the specimens are also quantified.

\section{EXPERIMENTAL SETUP}

\subsection{Specimens preparation}

The Arenga pinnata fibres were purchased from local people where the plant grows near Universiti Teknologi MARA in Kuala Pilah, Negeri Sembilan, Malaysia. The fibres were washed and rinsed thoroughly to remove unwanted contaminants and dirts. The fibres were then let dried at room temperature for a day before crushed. To obtain Arenga pinnata fibre in powder form, all dried fibres were crushed in two steps; using crushing machine to reduce its entanglement and finally the crushed fibres are milled for 3 hours via planetary ball mill machine. The milled fibres were lastly sieved using $0.25 \mathrm{~mm}$ mesh size sieve frame.

The density of Arenga pinnata particulates was determined using Micromeritics pycnometer with helium gas (AccuPyc II 1340, U.S.A, 2013) and all standard deviations measured were lower to $0.001 \mathrm{~g} / \mathrm{cm}^{3}$. The average density for the Arenga pinnata powder was reported to be about $1.5045 \mathrm{~g} / \mathrm{cm}^{3}$.
Silicone Ecoflex 00-30 (Platinum cure Silicone Rubber Compound) supplied by Castmech Sdn Bhd was chosen for the matrix to produce a soft composite material. The $12 \mathrm{wt} \%$ milled fibres were then added into silicone solution and ensured that the solution was well stirred. This is crucial to achieve the homogeneity between the fibres and the silicone solution.

\subsection{Uniaxial tensile test}

Tensile test was performed in Strength of Materials Laboratory, Universiti Teknologi MARA, Shah Alam using 3382 Universal Testing Machine $100 \mathrm{kN}$ (Instron, U.S.A, 2008). Therefore, nine specimens each for pure silicone rubber and $12 \mathrm{wt} \%$ Arenga pinnata-silicone biocomposite were prepared according to ASTM D412 standard as shown in Fig. 1. The ready specimen is clamped to the machine and the tensile test is conducted until failure state reached with $500 \mathrm{~mm} / \mathrm{min}$ speed rate.

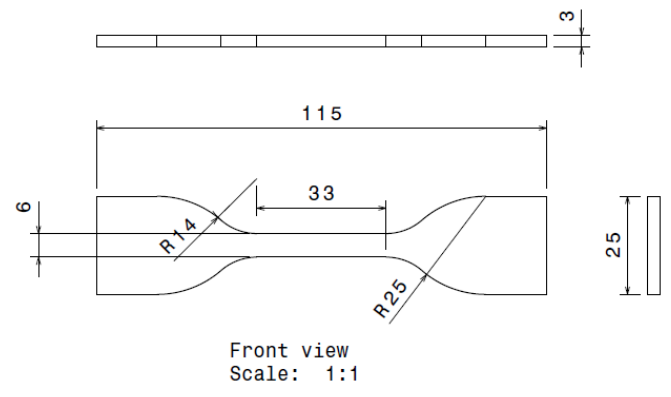

Fig. 1. Specimen size according to ASTM D412 standard

\subsection{Quantifying hyperelastic material constants}

Since the materials used in this study are soft and highly elastic, that their deformation behaves according to rubbery materials, it is assumed that these materials would fulfil hyperelastic theory. The deformation behaviour could be represented using hyperelastic stress-stretch relation. Therefore, hyperelastic constitutive equations were employed in this study to demonstrate the deformation behaviour of both silicone rubber and the $12 \mathrm{wt} \%$ Arenga pinnata-silicone biocomposite under tensile load. In this study, Neo-Hookean and Mooney-Rivlin models were selected because they were the two most common and easy to use. Considering both models as isotropic, incompressible and hyperelastic, they are expressed in terms of engineering stress, $\sigma_{\mathrm{E}}-$ stretch, $\lambda$ relation under uniaxial load as shown in Eq. 1 and Eq. 2 respectively [22].

$\sigma_{\mathrm{E}}=2 \mathrm{C}_{1}\left(\lambda-\frac{1}{\lambda^{2}}\right)$;

$\sigma_{\mathrm{E}}=\frac{1}{\lambda}\left[\left(2 C_{1}+\frac{2 C_{2}}{\lambda}\right)\left(\lambda^{2}-\frac{1}{\lambda}\right)\right]$.

Since Eq. 1 and Eq. 2 are expressed in terms of engineering stress-stretch, $\left(\sigma_{\mathrm{E}}-\lambda\right)$, relation, the engineering stress-strain, $\left(\sigma_{\mathrm{E}}-\varepsilon\right)$, data obtained previously from the uniaxial tensile tests (as mentioned in Section 2.2) are converted into engineering stress-stretch, $\left(\sigma_{\mathrm{E}}-\lambda\right)$ relation using Eq. 3.

$\lambda=1+\varepsilon .(3)$

Taking this data (the engineering stress-stretch curve from the experiments) as the reference, a curve fitting 
procedure is carried out using Eq. 1 and Eq. 2 to get the best match curves. The best match curve would constitute the material constant parameters that can accurately describe the mechanical behaviour of the materials under investigation. By doing this, the material constants; $\mathrm{C}_{1}$ (Eq. 1 for Neo-Hookean model); and $\mathrm{C}_{1}$ and $\mathrm{C}_{2}$ (Eq. 2 for Mooney-Rivlin model) are determined.

\subsection{Physical test}

Density test was conducted on pure silicone rubber and 12 wt.\% Arenga pinnata-silicone biocomposite specimens using Specific Gravity Measuring Kit (AD-1653, Japan, 2004) and the density values were calculated using:

$\rho=\left(\frac{A}{A-B}\right) \times\left(\rho_{O}-d\right)+d$,

where $\rho$ is the density; $A$ is the weight of the specimen in air; $B$ is the weight of the specimen in water; $\rho_{O}$ is the density of distilled water; $d$ is the density of air $\left(0.001 \mathrm{~g} / \mathrm{cm}^{3}\right)$.

\subsection{Morphological analysis}

The morphological analysis was carried out using TM3000 Scanning Electron Microscope (SEM) (Hitachi, Japan, 2012) in the Faculty of Dentistry, Universiti Teknologi MARA, Sungai Buloh on the break surface due to tensile load earlier. For a better image quality, the surface of the specimens to be examined was coated with platinum using sputter coater machine.

\section{RESULTS AND DISCUSSION}

\subsection{Tensile test}

Maximum tensile strength, $\sigma$ and maximum stretch, $\lambda$ for both specimens; pure silicone rubber and $12 \mathrm{wt} . \%$ Arenga pinnata-silicone biocomposite were analysed. Fig. 2 displays the average tensile properties for both specimens where $\mathrm{x}$ - and $\mathrm{y}$-axes represent stretch, $\lambda$ and engineering stress, $\sigma_{\mathrm{E}}$ respectively.

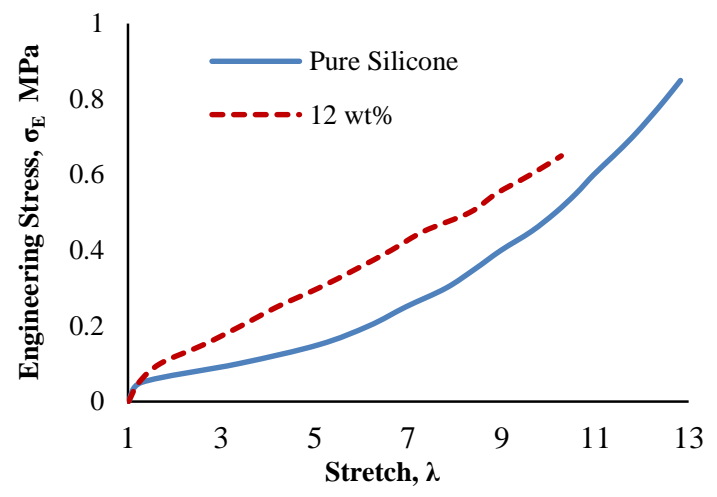

Fig. 2. Stress-stretch curves from tensile test for pure silicone rubber and 12 wt.\% Arenga pinnata-silicone biocomposite

In comparison, it can be observed that pure silicone rubber specimens possessed the highest tensile strength compared to $12 \mathrm{wt}$ \% Arenga pinnata-silicone biocomposite specimens. A similar behaviour has been reported by Chandran et al., where the increment of fibre content has resulted in lower tensile strength compared to $0 \%$ fibre loading [23]. Fig. 2 also shows that pure silicone rubber stretches the most under the tensile load and thus, this indicates that pure silicone is much more elastic than 12 wt.\% Arenga pinnata-silicone biocomposite. This indicates that the addition of Arenga pinnata fibres has reduced the highly nonlinear elastic behaviour of silicone rubber. Pure silicone rubber presents a highly nonlinear elastic behaviour with a concave upward curve, while 12 wt.\% Arenga pinnata-silicone biocomposite produce an almost linear curve. The average values of mechanical tensile properties of both specimens are tabulated in Table 1.

Table 1. Comparison of tensile properties between pure silicone rubber and $12 \mathrm{wt} . \%$ Arenga pinnata-silicone biocomposite

\begin{tabular}{|c|c|c|}
\hline Specimens & $\begin{array}{c}\text { Pure silicone } \\
\text { rubber }\end{array}$ & $\begin{array}{c}12 \mathrm{wt} \% \text { silicone } \\
\text { biocomposite }\end{array}$ \\
\hline $\begin{array}{c}\text { Ultimate tensile } \\
\text { strength, MPa }\end{array}$ & 0.85 & 0.65 \\
\hline Maximum stretch & 12.826 & 10.276 \\
\hline
\end{tabular}

\subsubsection{Hyperelastic material constants}

Fig. 3 highlights the nonlinear elastic behaviour of pure silicone using the data from tensile test. The best fitted curves for Neo-Hookean and Mooney-Rivlin models are also shown to mimic the behaviour. Apparently, it could be seen that both models could not perfectly demonstrate behaviour of the pure silicone rubber.

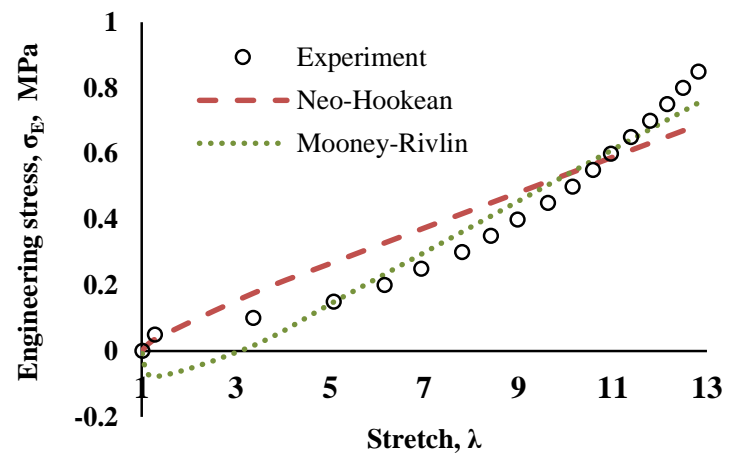

Fig. 3. Pure silicone rubber stress-stretch curves for Neo-Hookean and Mooney-Rivlin models compared to experiment

Neo-Hookean model could mimic accurately only at low stretch values up to 1.288. Moreover, the Neo-Hookean curve concaves downwards. Differ from the Neo-Hookean model, Mooney-Rivlin model exhibits negative stress values at low stretch values and then continues to increase almost linearly, where the stress values seem to directly proportional to stretch values. The Mooney-Rivlin model obviously demonstrated poor performance to mimic the highly nonlinear elastic behaviour of pure silicone rubber. These conditions somehow have been found to be similar in a study where Neo-Hookean model is only capable to mimic the tensile behaviour of silicone rubber at low strain values. The same study also reports that the Mooney-Rivlin model is unable to fit well their experimental data [24]. A similar finding was deduced by Martins et al, where they stated in their study that Neo-Hookean model showed worst performance to mimic a behaviour with highly non-linear pattern [25]. This is due to the limitation of the model with single material parameter $\left(\mathrm{C}_{1}\right)$ compared to other 
constitutive models.

Fig. 4 highlights the nonlinear elastic behaviour of 12 wt.\% Arenga pinnata-silicone biocomposite using the data from tensile test. The best fitted curves for NeoHookean and Mooney-Rivlin models are also shown to mimic the behaviour. Compared to pure silicone rubber (Fig. 3), it is interestingly to observe that both Neo-Hookean and Mooney-Rivlin models produce much better results, where the curves coincide with the experimental data. By filler addition, the specimen behaves less nonlinear and this allows both models to mimic well. This is similar to the study of Sasso et al, where the Mooney-Rivlin model (second order) demonstrated the rubber-like material behaviour exactly according to their experimental results [19]. Their graph displays almost similar pattern to the current 12 wt. $\%$ Arenga-pinnata-silicone biocomposite tensile behaviour but their stretch values are lower compared to the current study (Fig. 4).

Table 2 shows the material constants quantified from Neo-Hookean and Mooney-Rivlin models for both pure silicone rubber and $12 \mathrm{wt} \%$ Arenga pinnata-silicone biocomposite.

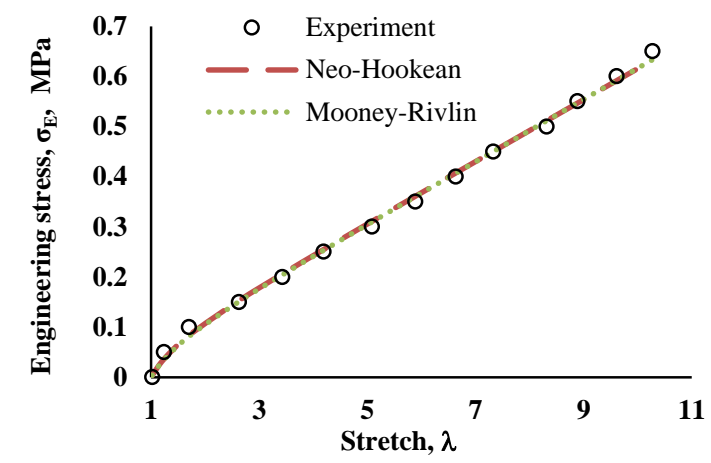

Fig. 4. 12 wt.\% Arenga pinnata-silicone biocomposite stressstretch curves for Neo-Hookean and Mooney-Rivlin models compared to experiment

Table 2. Neo-Hookean and Mooney-Rivlin material constants (MPa) for $0 \mathrm{wt} \%$ and $12 \mathrm{wt} . \%$ Arenga pinnata-silicone biocomposite

\begin{tabular}{|c|c|c|}
\hline Models & Neo-Hookean & Mooney-Rivlin \\
\hline 0 wt.\% & $\mathrm{C}_{1}=0.02683$ & $\begin{array}{c}\mathrm{C}_{1}=0.03907 \\
\mathrm{C}_{2}=-0.1234\end{array}$ \\
\hline $12 \mathrm{wt} \%$ & $\mathrm{C}_{1}=0.03081$ & $\begin{array}{c}\mathrm{C}_{1}=0.03104 \\
\mathrm{C}_{2}=-0.00171\end{array}$ \\
\hline
\end{tabular}

\subsection{Materials density}

From the density test, the results show that the addition of Arenga pinnata fibre has increased the density of the biocomposite material (Fig. 5). At 12 wt.\% Arenga pinnatasilicone biocomposite, the average density of the material is $1.0715 \mathrm{~g} / \mathrm{cm}^{3}$ while the average density of pure silicone rubber $(0 \mathrm{wt} . \%)$ is $1.0257 \mathrm{~g} / \mathrm{cm}^{3}$ which is significantly lower than $12 \mathrm{wt} . \%$ specimens. This is due to the fact that Arenga pinnata fibres are denser $\left(1.5045 \mathrm{~g} / \mathrm{cm}^{3}\right)$ than silicone rubber itself and thus increasing its physical density after it has been added into silicone rubber.

\subsection{Morphological characteristics}

The morphological analysis is conducted on the fractured surface of the specimens after destructive tensile test. It is to verify the failure pattern, fibre distribution and to observe the microstructural behaviour exhibits on both pure silicone rubber and $12 \mathrm{wt} . \%$ Arenga pinnata-silicone biocomposite.

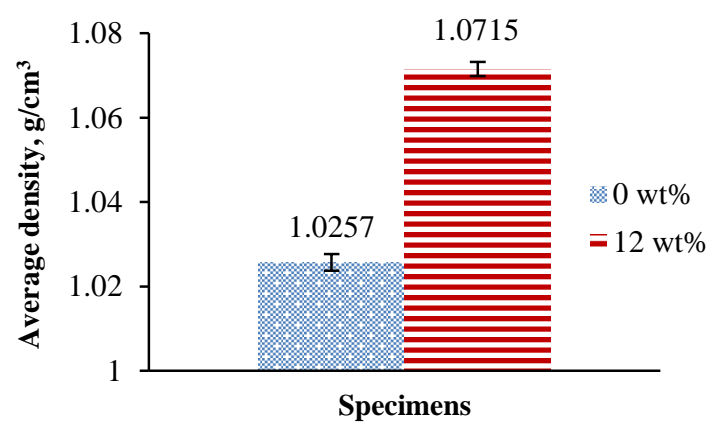

Fig. 5. Density values obtained from experiments for pure silicone rubber and $12 \mathrm{wt}$ \% Arenga pinnata-silicone biocomposite

Fig. 6 and Fig. 7 show the morphological of the break surface of pure silicone rubber and the silicone biocomposite respectively. Pure silicone rubber's image (Fig. 6) displays its physical surface without any filler. There are no voids and signs of failure due to tensile load that can be seen.

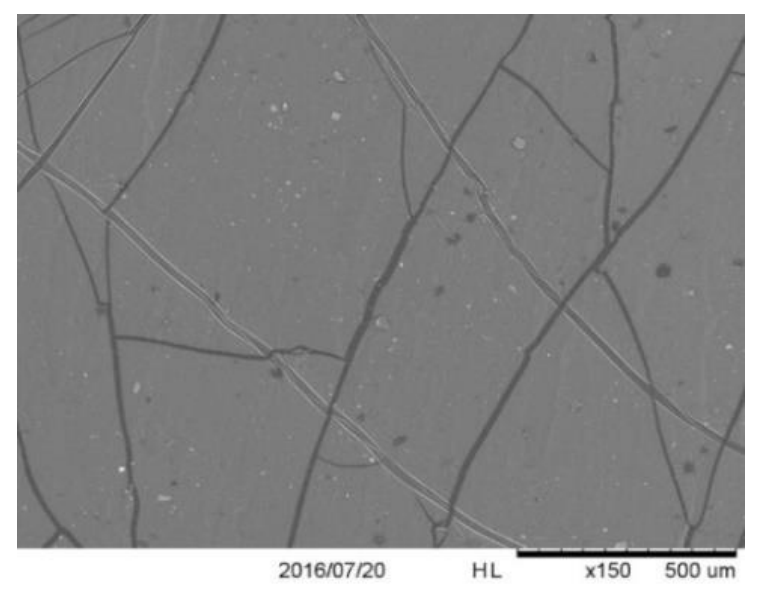

Fig. 6. SEM image of pure silicone rubber

Based from SEM images shown for $12 \mathrm{wt} \%$ Arenga pinnata-silicone biocomposite (Fig. $7 \mathrm{a}$ and b), it can be observed that the particulate fibres are well dispersed. No agglomeration can be observed throughout the break surface of the silicone biocomposite. However, the images also revealed that there are small voids formation which might due to the air trapped during the manual stirring process.

These voids might be one of the main factors that led to the first crack initiation to cause the material to fail. The surface area of the fibres also plays an important role in supporting good fibre-matrix adhesion. Large fibre surface area reduces adhesiveness to the matrix (silicone), which is hydrophobic. The weak bonding increased the tendency for the crack to spread over to the adjacent voids or weak fibre bonding, until specimen's rupture. As illustrated in Fig. 8, the crack will continue spreading to the nearest point where the bonding is weak. Unlike fibre with smaller surface area, the tendency to crack at that points are less and thus, ensuring good fibre-matrix bonding.

Not only that, the major influence of the filler addition has caused the fracture surface of silicone biocomposite to 
become rougher and coarser compared to pure silicone rubber where the surface is still smooth although it has been exposed to destructive tensile load. Obviously, the fibre addition indicates some patterns of failure which can be seen clearly in Fig. 7 b due to tensile load.

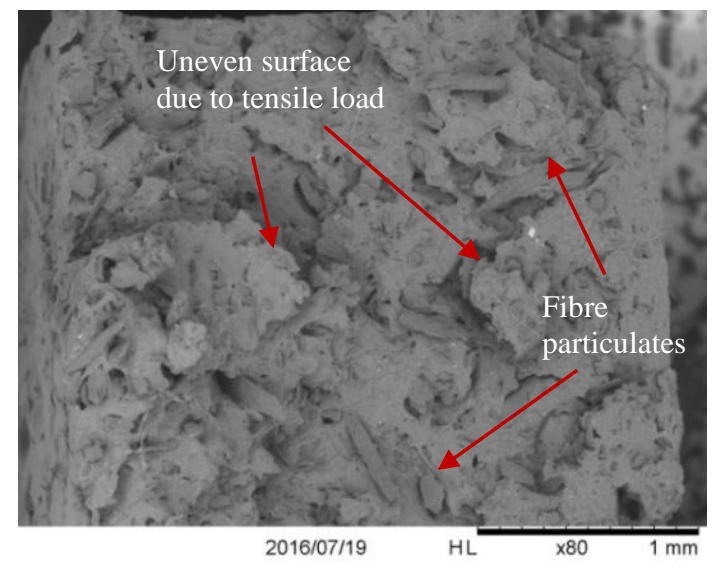

a

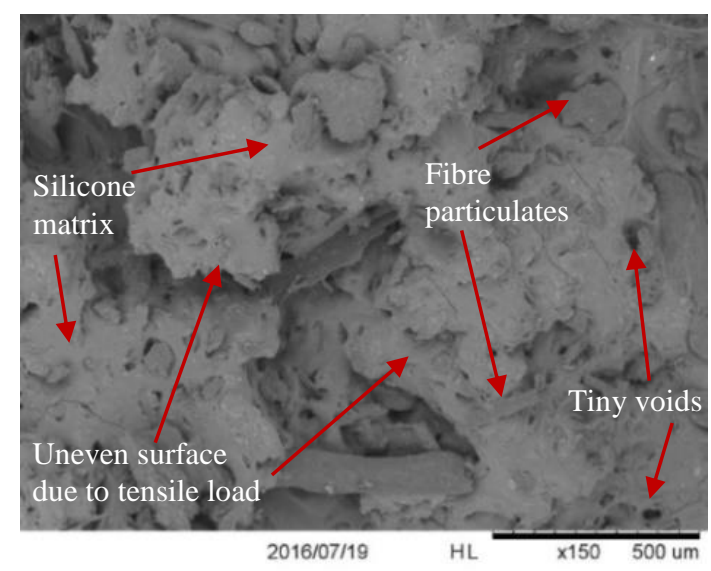

b

Fig. 7. SEM image for $12 \mathrm{wt} . \%$ Arenga pinnata-silicone biocomposite: a-with x80 magnification (upper side); $\mathrm{b}$ - with x150 magnification (lower side)

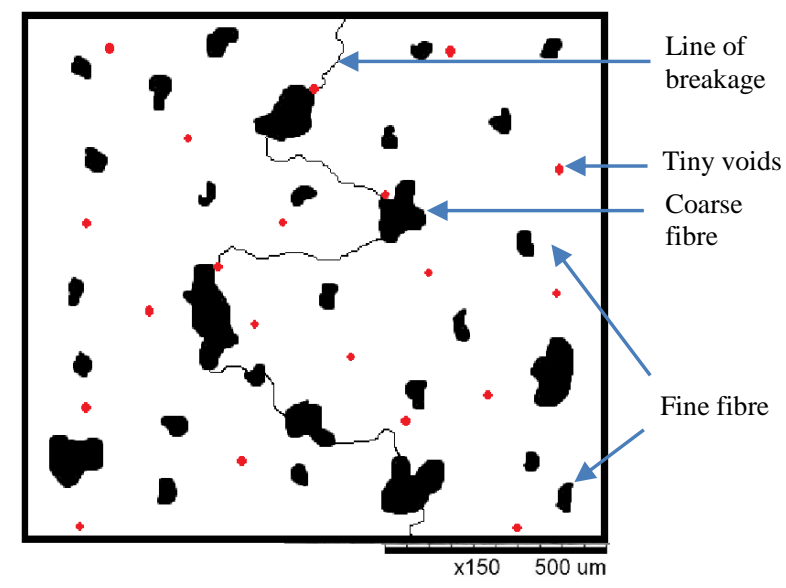

Fig. 8. Schematic diagram of the failure mode of the 12 wt.\% Arenga pinnata-silicone biocomposite

\section{CONCLUSIONS}

This study introduces new silicone biocomposite materials in the awareness of environmental issues for a greener and cleaner environment with the development of "green materials". Arenga pinnata fibres are chosen and it is proven that Arenga pinnata fibres give significant effects on silicone rubber as the stiffness and density of the materials have increased. In terms of hyperelastic investigations, the 12 wt.\% Arenga pinnata-silicone biocomposite shows both models especially Mooney-Rivlin model displays that it can almost mimic the experimental tensile curve. SEM images of the silicone biocomposite also show good adhesion bonding and dispersion among Arenga pinnata fibre and the silicone rubber. Thus, the aim of this study has been achieved. These new findings could contribute to new development in biomaterials in enhancing safer and cleaner environment. In fact, more researches on this silicone biocomposite will be explored and further findings shall be reported in the near future.

\section{Acknowledgments}

This work is supported by the Ministry of Higher Education (MOHE) Malaysia and Universiti Teknologi MARA. (Fundamental Research Grant Scheme, grant no. 600-RMI/FRGS 5/3 (0098/2016)).

\section{REFERENCES}

1. Rwawiire, S., Tomkova, B., Militky, J., Jabbar, A., Kale, B.M. Development of a Biocomposite Based on Green Epoxy Polymer and Natural Cellulose Fabric (Bark Cloth) for Automotive Instrument Panel Applications Composites Part B Engineering 81 2015: pp. 149-157. https://doi.org/10.1016/j.compositesb.2015.06.021

2. Sanyang, M.L., Sapuan, S.M., Jawaid, M., Ishak, M.R., Sahari, J. Recent Developments in Sugar Palm (Arenga pinnata) Based Biocomposites and Their Potential Industrial Applications: A Review Renewable and Sustainable Energy Reviews 54 2016: pp. 533-549. https://doi.org/10.1016/j.rser.2015.10.037

3. Sahari, J., Sapuan, S.M., Zainudin, E.S., Maleque, M.A. Mechanical and Thermal Properties of Environmentally Friendly Composites Derived from Sugar Palm Tree Materials \& Design 49 2013: pp. 285-289. https://doi.org/10.1016/j.matdes.2013.01.048

4. Anbukarasi, K., Kalaiselvam, S. Study of Effect of Fibre Volume and Dimension on Mechanical, Thermal, and Water Absorption Behaviour of Luffa Reinforced Epoxy Composites Materials and Design 66 2015: pp. 321-330. https://doi.org/10.1016/j.matdes.2014.10.078

5. Peşman, E., Tufan, $\mathrm{M}$. The Effects of $\mathrm{CaCO}_{3}$ Coated Wood Free Paper Usage as Filler on Water Absorption, Mechanical and Thermal Properties of Cellulose-High Density Polyethylene Composites Materials Science (Medžiagotyra) 22 (4) 2016: pp. 530-535.

http://dx.doi.org/10.5755/j01.ms.22.4.14222

6. Fowler, P.A., Hughes, J.M., Elias, R.M. Review Biocomposites: Technology, Environmental Credentials and Market Forces Journal of the Science of Food and Agriculture 87 2006: pp. $1781-1789$.

https://doi.org/10.1002/jsfa.2558

7. Gurunathan, T., Mohanty, S., Nayak, S.K. A Review of the Recent Developments in Biocomposites Based on Natural Fibres and Their Application Perspectives Composites: Part A Applied Science and Manufacturing 77 2015: pp. 1-25. https://doi.org/10.1016/j.compositesa.2015.06.007 
8. Abdullah, A.H., Razali, M.R.M., Ghani, M.A.A. Thermal Modulus Evaluation of Arenga pinnata Fibre Reinforced Epoxy Composite: Effect of Moisture Absorption Advanced Materials Research 911 2014: pp. 18-22. https://doi.org/10.4028/www.scientific.net/AMR.911.18

9. Ticoalu, A., Aravinthan, T., Cardona, F. A Review on The Characteristics of Gomuti Fibre and Its Composites with Thermoset Resins Journal of Reinforced Plastics and Composites 32 (2) 2013: pp. 124-136. https://doi.org/10.1177/0731684412463109

10. Ishak, M.R., Sapuan, S.M., Leman, Z., Rahman, M.Z.A., Anwar, U.M.K., Siregar, J.P. Sugar Palm (Arenga pinnata): Its Fibres, Polymers and Composites Carbohydrate Polymers 91 2013: pp. 699-710. https://doi.org/10.1016/j.carbpol.2012.07.073

11. Khudhur, P.A., Zaroog, O.S., Khidhir, B.A., Radif, Z.S. Fracture Toughness of Sugar Palm Fiber Reinforced Epoxy Composites International Journal of Science and Research 2 (12) 2013: pp. 273-279.

12. Ain, M.R.F., Yusof, Y.A., Chin, N.L., Dom, Z.M. Storage Study of Arenga Pinnata Juice Agriculture and Agricultural Science Procedia 2 2014: pp. 218-223. https://doi.org/10.1016/j.aaspro.2014.11.031

13. Wang, L., Cheng, L. Piezoresistive Effect of a Carbon Nanotube Silicone-Matrix Composite Carbon 71 2014: pp. 319-331. https://doi.org/10.1016/j.carbon.2014.01.058

14. Gao, B.Z., Xu, J.Z., Peng, J.J., Kang, F.Y., Du, H.D., Li, J., Chiang, S.W., Xu, C.J., Hu, N., Ning, X.S. Experimental and Theoretical Studies of Effective Thermal Conductivity of Composites Made of Silicone Rubber and $\mathrm{Al}_{2} \mathrm{O}_{3}$ Particles Thermochimica Acta 614 2015: pp. 1-8. https://doi.org/10.1016/j.tca.2015.06.005

15. Raza, M.A., Westwood, A., Brown, A., Hondow, N., Stirling, C. Characterisation of Graphite Nanoplatelets and the Physical Properties of Graphite Nanoplatelet/Silicone Composites for Thermal Interface Applications Carbon 49 2011: pp. $4269-4279$. https://doi.org/10.1016/j.carbon.2011.06.002

16. Song, Y., Yu, J., Dai, D., Song, L., Jiang, N. Effect of Silica Particles Modified by In-Situ and Ex-situ Methods on the Reinforcement of Silicone Rubber Materials and Design 64 2014: pp. $687-693$. https://doi.org/10.1016/j.matdes.2014.08.051

17. Yan, F., Zhang, X., Liu, F., Li, X., Zhang, Z. Adjusting the Properties of Silicone Rubber Filled with Nanosilica by
Changing the Surface Organic Groups of Nanosilica Composites Part B: Engineering 75 2015: pp. 47-52. https://doi.org/10.1016/j.compositesb.2015.01.030

18. Manan, N.F.A., Ramli, M.H.M., Patar, M.N.A.A., Holt, C., Evans, S., Chizari, M., Mahmud, J. Determining Hyperelastic Parameters of Human Skin Using 2D Finite Element Modelling and Simulation 2012 IEEE Symposium on Humanities, Science and Engineering Research 2012: pp. 805-809. https://doi.org/10.1109/SHUSER.2012.6268996

19. Sasso, M., Palmieri, G., Chiappini, G., Amodio, D. Characterization of Hyperelastic Rubber-Like Materials by Biaxial and Uniaxial Stretching Tests Based on Optical Methods Polymer Testing 27 2008: pp. 995-1004. https://doi.org/10.1016/j.polymertesting.2008.09.001

20. Groves, R.B., Coulman, S.A., Birchall, J.C., Evans, S.L. An Anisotropic, Hyperelastic Model for Skin: Experimental Measurements, Finite Element Modelling and Identification of Parameters for Human and Murine Skin Journal of the Mechanical Behavior of Biomedical Materials 18 2013: pp. $167-180$. https://doi.org/10.1016/j.jmbbm.2012.10.021

21. Fereidoonnezhad, B., Naghdabadi, R., Arghavani, J. A Hyperelastic Constitutive Model for Fiber-Reinforced Rubber-Like Materials International Journal of Engineering Science 71 2013: pp. 36-44. https://doi.org/10.1016/j.ijengsci.2013.06.001

22. Noor, S.N.A.M., Khairuddin, M.A.F., Mahmud, J. Biocomposite Silicone: Synthesis, Mechanical Testing and Analysis New Developments in Mechanics and Mechanical Engineering 2015: pp. 113-117.

23. Chandran, V., Raj, T.M., Lakshmanan, T. Effect of Recycled Rubber Particles and Silica on Tensile and Tear Properties of Natural Rubber Composites Materials Science (Medžiagotyra) 22 (2) 2016: pp. 256-261. http://dx.doi.org/10.5755/j01.ms.22.2.7330

24. Kim, B., Lee, S.B., Lee, J., Cho, S., Park, H., Yeom, S., Park, S.H. A Comparison Among Neo-Hookean Model, Mooney-Rivlin Model, and Ogden model for Chloroprene Rubber International Journal of Precision Engineering and Manufacturing 13 (5) 2012: pp. 759-764. https://doi.org/10.1007/s12541-012-0099-y

25. Martins, P.A.L.S., Jorge, R.M.N., Ferreira, A.J.M. A Comparative Study of Several Material Models for Prediction of Hyperelastic Properties: Application to Silicone-Rubber and Soft Tissues Strain 42 2006: pp. 135-147. https://doi.org/10.1111/j.1475-1305.2006.00257.x 